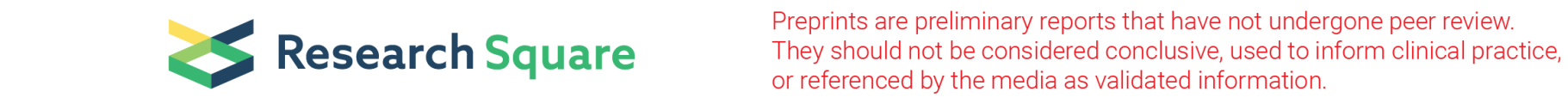

\section{Determining the Psychosocial Needs of ElderlyPeople Living in the Turkish Republic of Northern Cyprus}

samineh esmaeilzadeh ( $\square$ samineh_khalilazar@yahoo.com )

Near East University https://orcid.org/0000-0001-7390-499X

Fatma $\mathrm{Oz}$

Near East University

\section{Research article}

Keywords: Aging;Psychosocial needs; Elderly; Focus group method.

Posted Date: August 19th, 2019

DOl: https://doi.org/10.21203/rs.2.13175/v1

License: @ (i) This work is licensed under a Creative Commons Attribution 4.0 International License. Read Full License 


\section{Abstract}

Background:The Turkish Republic of Northern Cyprus (T.R.N.C.) is an island country that has experienced war due to its geographical location, and which has had a tragic recent history. It is believed that those who are currently elderly mayface many psychosocial problems as individuals who have experiencing this historical process. Identifying these psychosocial problems will help to planpsychiatric services for these individuals. Methods: The data was collected through focus group interviews, which are a qualitative research method. 20 elderly people aged 65 and above living in Northern Cyprus were interviewed on a voluntary basis. Therewere 6-8 people in each focus group. A questionnaire developed by the researchers was utilised during the interviews. Results:After the focus group interview, we divided the results into four categories (psychological, spiritual, physical and socialneeds) and 12 sub-themes:thepsychological categorycontainedlosses and emotional loneliness, risk of depression and adaptation to being elderly; thespiritual categorycontained anxiety aboutdeath, and beliefs, values and culture; thesocial category containedchange in roles, change in expectations, family problems and loneliness, and the physical category containedphysical impairment due to elderliness and illnesses. Conclusion:When comprehensive and realistic information is collected regarding the psychosocial needs and problems of elderly individuals, problems that are currently tending to increase, and the expectations of elderly people are properly understood, it is possible to develop new practical models that contribute to the enhancement of services for the elderly.

\section{Background}

As the quality of life increases, the human life span is extended and the population of elderly people increases[1].Aging is a life-long change and development process. Being elderly is an inevitable and irrevocable period that is comprised of unique biological, physiological and socio-economic characteristics[2]. While the periods of infancy, childhood, adolescence and adulthood are considered as growth phases, the period of elderliness is usually considered as a decline. Elderliness is a period where an individual suffers physical impairments with adecrease in abilities, and in which one is more dependent on the environment and faces more mental problems. On the other hand, despite physiological issues, elderliness may notbe a period of decline, but a period in which psychosocial growth continues[3, 4].

The World Health Organisation defines aging for those aged 65 and over as "the constant decline of vital functions and efficiency of an individual, and of the ability to adapt to environmental functions" [5, 6].Aging is mainly analysedin terms of its chronological, biological, psychological and social dimensions[7,8].It is clear that family structures and society have been affected by the influx of population to urban areas since the early $20^{\text {th }}$ century, and the concept of the extended family has been replaced with the concept of nuclear family. Parents are left increasingly alone and unable to solve problems after their children start working and move out of the house, which generally makes the elderly individuals feel desperate, defenceless and alone[9].Therefore, the psychological needs of aging individuals have become significant and an important social issue. Elderly individuals with difficulties in adapting to new circumstances, slower mental functions, and who depend on others in order to sustain their daily lives, may start to have emotional problems such as feelings of inadequacy and uselessness, and it may become easier for various psychiatric problems to emerge[10].

Physical changes that occur in aging cause problems in psychosocial domain as well. Together with the social changes, the increase in the number of elderly individuals and life expectancy require that relevant measures be taken and thatthe number of support systems be increased[4].

With regard to the status of elderly and aging as indicated under the National Action Plan, the aim is to ensure successful and independent aging in terms of productivity, and the physical, psychological and social dimensions, while the policies and programs focus on improving the quality of life and general health[11].Assisting and supportingtheindividual, who is in a vulnerable phase as a result of changes intheir roles and responsibilities during aging, or various negative circumstances such as illnesses and disabilities, is thus vital[12]. The basis of elderly services is to ensure that the elderly feel self-efficient and happy individual. Having access to such services is a right for elderly people and it is a responsibility of society to provide them. It is crucial for the elderly to be able to live out their lives in a peaceful way so that younger generations can be hopeful for their own future. Hence, the problems of elderly should be evaluated from every point of view[13]. 
Within the TRNC, individuals aged 65 and over comprised $7.54 \%, 8.1 \%$ and $10.7 \%$ of the total population according to the 2006 , 2011 and 2015 data respectively [14].

In the TRNC, elderly services are provided by the state, and there are public care homes, rehabilitation centres, private care homes and nursing homes[15]. Additionally, there are "service for the elderly projects" for elderly individuals in many municipalities.

It is crucial that initiatives be provided for the elderly, who form a considerable proportion of the population of TRNC, to enable them to solve their own problems, live independently, and to support them as much as possible in participating in society. Such initiatives are vital in positively affecting the quality of life of elderly individuals. Healthy aging is not only related to individual characteristics but also closely linked with support services forthe psychosocial, economic and physiological aspects of aging. Since feelings of physical, social, economic and psychic inadequacy are more dominant particularly during this period, the services for elderly must be holistic.

Nurses have a significant responsibility in helping elderly people cope with stress by supporting their adaptation to their level of wellness, illness or the existing environment, and in providing the services they need. Just in any other phase of life, being elderly comes with new changes, experiences and problems.Identifying how to handle reactions to aging, maximizing strength and maintaining the integrity of elderly peoplewould be helpful to the nurses in fulfilling their responsibility[16].

\section{Methods}

The research was conducted as a qualitative studyusing focus group interviews to identify the needs and problems of elderly individuals living in the town of Dikmen, TRNC.The population of research consisted of elderly people aged 65 and over, who applied to the health centre in Dikmen. There were two nurses working at the municipal health centre, which was located in the centre of Dikmen. The villages in the municipality are provided with elderly care services once a month by home visits. Data saturation was reached when the sample had a total number of 20 elderly individualsaged 65 and over who had applied to the health centre and volunteered to participate. Three focus group interviews were conducted with each group of 6-8 people.

\section{Data collection}

The research data are collected through focus group interview method. The open-ended questions used in the focus group interviews were about perceptions of aging, perceptions about their own lives, opinions/ideas about aging, changes caused by aging, their needs and how they fulfilled their needs, situations that required support and the situations that affect them at the most.Additionally, there were also questions about characteristics, such as age, gender, marital status, having a child and social security, that are considered to have a possible effect on the needs and problems of the elderly. The focus groups were formed from among the elderly individuals living in Dikmen who met the inclusion criteria between 6 and20 July 2018, and the needs and problems of these elderly individuals were determined accordingly. The size of each focus group was recommended to be between 4 and 9 people[17].For this study, each focus group interviewwas conducted with 6-8 people. In addition to the 6-8 elderly people, there were also the researcher and rapporteur. The data were recorded in writing through the rapporteur. The rapporteur was informed in advance about the aim of research, the interview questions and how the answers would be written. Before the interview, the researcher introduced himself/herself and provided information aboutthe research, and then the group members were requested to introduce themselves. The rapporteur recorded the answers given by the elderly individuals, and their needs, feelings and opinions were also recorded. Interviews were conducted with a total of 20 individuals from three groups on the 6, 13 and 20 July 2018 . A meeting room at Dikmen Health Centre meeting room was used as the location for the focus groups. Each meeting took between 90 and 120 minutes. After each group meeting, the notes taken by the researcher and rapporteur were documented.

\section{Data analysis}

The research data were evaluated in two phases: log development (documentation) and content analysis. With regard to the log development, each focus group meeting was documented in writing. Each participant was given a participation code in advance based on his or her residence and gender, and the log development form was converted into a written format. Following the log development, data coding, identification of sub-themes, organisation and interpretation of codes and themes were performed during content analysis. Four experts were consulted with regard to this process in order to ensure the reliability of the categories and subthemes. The categories and sub-themes were identified in accordance with the expert opinion.

Page $3 / 11$ 


\section{Results}

In terms of thebasic characteristics of the participants, $75 \%$ were $65-75$ years-old, and $25 \%$ were 75 or over. $30 \%$ were female and $70 \%$ male. $75 \%$ of the participants were married while $25 \%$ were widowed. $65 \%$ were retired while $10 \%$ were employed. All the participants had children.

Following the focus group interviews, the psychosocial needs of elderly were placed into four categories: psychological, spiritual, social and physical needs(Table 1).

Psychological category: The psychological category was divided into thethemes of losses, loneliness, risk of depression and adaptation to being elderly. Under the losses theme, there were the sub-themes of loss of independence and loss of strength. The loneliness theme was divided into the sub-themes of loss of spouse and loss of loved ones sub-themes. The risk of depression theme consisted of the sub-themes of feeling of unworthiness, regret, feeling of inadequacy due to physical problems, lack of hope and sadness and feeling low energy. Under the adaptation to being elderly theme, there were the sub-themes of positive attitudes/thoughts about being elderly, acceptance, and negative attitudes/thoughts about being elderly.

Spiritual category: the spiritual category was divided into of themes of anxiety about death, and beliefs, values and culture. The anxiety about death theme consisted of the sub-themes of regrets about the past, uncertainty about the future and the fear of losing loved ones. The beliefs, values and culture theme consisted of the sub-themes of desire of talking about the past-Longing to past (comfort).

Social category: the social category was divided into the change in roles, change in expectations, family problems and loneliness themes. The theme of change in roles consisted of the sub-themes of loss of role, becoming a grandparent (responsibility) and adaptation to retirement. The change in expectations theme included the sub-themes of enjoying free time (drawbacks) and expectations from children. The sub-theme of family problems included the sub-themes of communication problems with the spouse (inadequacy in family communication) and the burden of care due to the health issues of spouse. The loneliness theme included the sub-themes of physical burden, social isolation, work environment and feelings of alienation from friends.

Physical category: the physical category was divided into the themes of physical losses due to elderliness, and illnesses. The loss of functional competence, change in body image, and not being active were sub-themes within the physical losses due to elderliness theme.

Some of the statements regarding the themes and sub-themes under the category of psychological needswere as follows:

Losses:

"When you get old, you are not physically sound and strong; this is such a bad feeling. I'm dependent on others, but I still do my own work, what should I do? Should I just sit and wait for other people?" (2W)

"When you get old, you either become weak or sick and you become dependent on a care-taker and children. I don't even go out, I just stay at home. Either my children come and take me somewhere or my friends come and take me to the coffeehouse; I've been wanting to go to Karpaz for long time now, but who would come with me?" (2M)

\section{Loneliness:}

"Thankfully my children often visit me. I handle the housework by myself and they help me too. I also have friends and I am not in need of anyone. I can cook and I like it. After the loss of my wife, I did to feel alone, sometimes I feel very bad at nights as if there is something sitting on my chest; I just cry." (5M)

"I started to feel bad after the loss of my spouse; it has been ten years, which mean I've been alone for ten years."(9W) 
Depression risk:

“Being old is very bad; the words are not enough. Me and my wife always have problems; we don't have any joy, yet I don't ask for anything."(1M)

"You feel bad when you think that this is what they call life and it is over."(5M)

"Being old is bad, think about it, everything is becoming worse."(16M)

Adaptation to being elderly:

"Actually being elderly is a good thing; of course, it is when you don't have any illness. Other than that, you have grandchildren and it is such a good feeling; for example, if I was not old, I would not be able to sit here right now and just work. I call it 'the second spring."'(13M)

"I don't like when they call me old."(17M)

Some of the statements regarding the themes and sub-themes in the spiritual needs category were as follows:

Death anxiety:

"I feel anxious that something will happen when my spouse leaves home; I also think about the children too."(11M)

"I suffered a lot; my husband used to drink, he made me suffer a lot; I am fine now, I wish it hadn't happened like this."(8W)

Beliefs, values and culture:

"It will not be comfortable to have to move. I would want to be in my home.When you are stuck in bed and your child does not take care of you, then you have to live in a care home, but I don't want that either. Then again a carercould come at home, which is much better, but if there is somewhere to go during the day, I might go but l'd have to think about it, there are people that I don't know. I know and I feel comfortable around the people at the coffeehouse. I should try it."(3M)

"Chatting with neighbours makes me happy; we talk about the past" (8W)

Some of the statements regarding the themes and sub-themes in the social needs category were as follows:

Change in roles:

"If there is anything to do to pass the time without making you exhausted after retirement, then that is good; otherwise you would get bored; you'd spend time at the coffee shop. I recommend spending time in the garden."(13M)

"I take care of my grandchild; my daughter works so who would take care of that child. What can she do about it, I sometimes feel exhausted" (8W)

"We got old and a lot has changed in our lives; my wife passed away and I rarely see my children; I have a carer. I even need someone to talk to; my friends come and take me out otherwise I would stay at home; you can't work anyway as an old person."

(20M) 
Change in expectations:

"What can an old person do anyway?Just nothing, the men spend their free time at the coffee shop."(14M)

"Someone has to take me to the doctor; there needs to be one person with me to remind me to take my medication; I have many needs during the day. My spouse is very old and children are not always around."(1M)

"I want my children to visit but not only because we want them to. They have things to do.We took care of them, they should take care of us too." $(2 \mathrm{~W})$

"I am sorry for my husband; I take care of him and I ask for help from my children when I need to. He would be offended if they didn't come. I can understand them but he doesn't. I am both the woman and man in the house; I would be ashamed of bringing someone into our home to help. I have five children.My husband has not left the house since his surgery. He can't hear that well and grumbles at me. That's the reason that I go to work. At home, he always argues with me. I wouldn't have got married if I knew then what I know now. I said I would not get married then but I did."(2W)

"My spouse's health problemsmake me very sad.He/she can't walk yet he/she wants to go out for a picnic but he/she can only sit in one place when we go."(13M)

Loneliness:

“My husband is sick and can't walk. He doesn't leave home, it is difficult for him to leave. He uses a walking stick. He doesn't leave the house even though I want to."(1M)

"Yes, I know that he doesn't want anybody to see him using a walking stick, that's why he stays at home." (6W)

Some of the statements regarding the themes and sub-themes in the physical needs category were as follows:

Physical losses due to elderliness:

"I think about the past when I used to do everything by myself, now I ask help from my children."(2W)

"I love nature and I walk as much as I can. I used to eat whatever I want and do sports when I was young. Now I have to track what I eat as I can't walk a lot." (16M)

Illnesses:

"It's very bad. An old person has endless problems. I don't know what to do about the pain in my leg. It is a big problem. It feels like as if my legs are following me." (7W)

"I would say that it is a good thing if I wasn't sick. But an old person has a lot of problems including illnesses. I am afraid of being sick. I don't want to be sick."(12M)

\section{Discussion}

Where the statements on psychological needs were analysed, losses, loneliness, the risk of depression, and adapting to being elderly were all found. Losses occur as people start to age. The loss of spouse, friends, and status due to retirement and ill-health create a feeling that life is pointless[12]. 
Risk factors for depression are complex and multifactorial [18].During aging, the change in the quality of life, and physical health problems and losses might cause loneliness to arise, and such feelings might threatenthe mental healthof elderly individuals.Decline in the trust towards other people, decline in financial support, anger, stress and fear of being exposed to violence might cause alienation and loneliness in an elderly individual[19].

Considering the statements, the fact that the participants felt regret, inadequacy due to physical illnesses, lack of hope, sadness and low energysuggest a risk of depression. The most frequent mental illness encountered in the elderly is depression[20, 21]. According to a study bySucuoğlu conducted in 2012 in urban Nicosia to identify how individuals aged 65 and over maintained their daily life activities and their incidence of depression, the frequency of depression in elderly individuals was $30.9 \%[22]$.

With regard to the statements, there were an equal number of positive and negative statements about being elderly. The perception of aging is one of the indicators that determines attitudestowards aging and has been a subject of scientific research since the1930s[23].

The individual's assumptions about their future health can be analysed with by identifying their level of satisfaction about their existing age and their adaptation to changes[24]. Aközerassessedaging and the perceptions of elderly individuals, and foundthe perceptions of the elderly towards aging to benegative (13.3\%), positive (84.0\%) and very positive (2.7\%)[25]. With regard to the statements made, those that reflect anxiety about death, including regrets about the past and losing their loved ones, stand out.

Spirituality, or theworld-views and beliefs of individuals, affects their attitudes, beliefs, values and health across their lives. It can addmeaning to the life, and help people to find the meaning in their pain by influencing their capacity to trust, love and forgive. Spiritual difficulties may arise in different ways. Such difficulties occur when a person loses a sense of meaning in their lives, believes they have no purpose or experiences feelings of hopelessness [16].In the related literature, anxiety about death is one of the factors that causes psychological illnesses among elderly individuals. The idea of death gives rise to anxiety in individuals but this may serve to reconcile the individual to life and provide meaning to their existence. It is possible to live a meaningful life when the reality of death is acknowledged [25]. Regrets about the past are considered as one of the factors that cause anxiety about death[26].In a number of studies regarding the elderly, it has been suggested that psychological services are provided to enable the aging population to acceptand be prepared for death, and not to be afraid[13].

All of the participants had negative opinions about care homes. Research has shown that elderly individuals prefer to receive care in their own homes. For these reasons, the provision of home care services has become significant. Home care services are provided by the professional organisations and include a number of domains such as health, economic and social services for elderly people who cannot receive such care fromtheir relatives[27]. On the other hand, studies about the care homes indicate that they are preferred by elderly individuals who are in need of services such as physical care, companionship and therapy and who are financially insecure[28].

The focus group members showed a tendency to tell stories about the past during the focus group interviews. Elderly people often have clear memories about their past lives and they enjoy remembering their past and sharing these memories with people who will listen to them. The "reminiscence method", first used during a group study conducted by Ebersole in 1976, has become part of psychological services for older individuals in European countries[29].

When the statements about social needs were analysed, issues such as a change in roles, change in expectations, family problems and loneliness were found. Family and society play a fundamental role in the protection, care and support of elderly. Although it seems that the spouse has the biggest role in the care of theelderlyindividual, the children are often expected to fulfil such a role due to the infirmities caused by aging; hence children become major source of support and communication.

The loss of roles or having fewer roles during the retirement negatively affects the elderly person's senseof belonging to their occupation, family and society. New and enjoyable activities need to be introduced toreplace past activities during the adaptation to elderliness, otherwise feelings of alienation from the society may be experienced and the elderly individual maybe left to themselves and feel alone. When the retirement occurs in an expected and desired way, this does not cause any mental difficulties and one can enjoy being a retired person. The opposite of this situation might cause psychosocial stress. It should be taken into consideration that people who have been forced to retired or whose retirement has not been planned may be at risk of alcoholism and depression.

Page $7 / 11$ 
Therefore, it is important that an elderly individual who can work and be more or less productive is able to benefit from this; this could help that person to feel useful[30].

Difficulties experienced in the social environment affect individuals in a negative way. Loneliness is caused by qualitative and quantitative deficiencies in a network of social relations. According toPeplauand Perlman (1984), loneliness is an unpleasant psychological situation due to the difference between the existing and desired social relations.Such an unpleasant situation might be considered to be related tosituations such as dissatisfaction, unhappiness, anxiety and shame [31].

With regard to physical needs, there are physical impairments related to being elderly and illnesses experienced. According toErci etal. elderly peoplewho had a better ability to care for themselveshad betterlife satisfaction and levels of hope [32].The identification of behaviours showing psychosocial problems, and the development of effective management skills,improve the chance that the patient will get better and minimize the frustration of nurses. Individualsfaced with illnesses and difficult situationsreact differentlybased on their past life experiences, coping strategies and characteristics; hence nursing should use a holistic structure that defines an individual and their own surroundings as a whole[16].

The health of elderly people should be considered in a holistic way. In elderly services a nurse should be aware of being a member of a multi-disciplinary team, know how to handle the psychosocial, emotional, environmental and physical skills, problems and needs of elderly individuals in order to provide effective and quality care, and should focus on providing psychological support to maintain and develop health.

\section{Conclusion}

There is a need to develop practices and methods to minimize the impacts of problems of aging on the daily lives of elderly, and to diversify services accordingly. Nurses havea pioneer role in establishing social environments to care for elderly adults, performing psychosocial interventions based on their needs and being aware of better methods and models that provide a scientific basis to nursing practices.New, comprehensive, practical models should be developed in order to reduce the psychosocial care needs of elderly individuals. Hence, nurses should have a full and realistic knowledge ofthe psychosocial needs and problems experienced in, and be able to evaluate the factors that affect the mental health of elderly individuals.

\section{Abbreviations}

T.R.N.C:Turkish Republic of Northern Cyprus

W: Woman

M: Man

\section{Declarations}

\section{Ethical approval and consent to participate}

Before the interviews, all participants were informed about the purpose of the study and interviews, and of procedures regarding the recording and treatment of data. To carry out the research, written permission was obtained from the Dikmen Municipality Directorate (85/18) and approved by the Scientific Research Evaluation Ethics Committee of Near East University (Reference number: 2018/59-611).

\section{Consent for publication}

Not applicable.

\section{Availability of data and materials}

The datasets used and/or analysed during the current study are available from the corresponding author on reasonable request.

\section{Competing interests}

Page $8 / 11$ 
The authors declare that they have no competing interests.

\section{Funding}

Not applicable.

\section{Authors' contributions}

SM was responsible for the initial draft of the manuscript.SM and FO were responsible for the design of the study.SM was responsible for data extraction.SM and FO wereresponsible fordata analysisand interpretation of data.SM and FO contributed to the drafting of the manuscript. SM and FO read and approved the final manuscript.

\section{Acknowledgments}

We would like to offer our special thanks to those who participated in this study.

\section{References}

1. Tambağ, H., Öz, F. Psikoeğitiminin Use of Group Psychoeducation in Nursing Care of Elderly. Journal of Hacettepe University Faculty of Nursing. 2014;1(3).47-53.

2. Bulduk, Ö. E. Ageing and Social Change. The Journal of Turkish Social Research. 2014;18(2), 53-60.

3. Öz, F. “Psychosocial Characteristics in Old Age”.Sosyal Hizmetler Dergisi.1999; 1(9), 19-27.

4. Öz, F.YThe Last Stage of Life: Elderty The Revievv of Psychosocial Dimension. Crisis Journal.2000; 10(2): 17-28.

5. The uses of epidemiology in the study of the elderly : report of a WHO Scientific Group on the Epidemiology of Aging [meeting held in Geneva from 11 to 17 January 1983] http://www.who.int/iris/handle/10665/39136

6. Heikkinen, Riitta-Liisa \& WHO Ageing and Health Programme. (1998). Growing older - staying well : ageing and physical activity in everyday life / prepared by Riitta-Liisa Heikkinen. World Health Organization. https://apps.who.int/iris/handle/10665/65230

7. Kaptan, G. Principles of Geriatric Care. 2013;s.1-10. Nobel Medicine Books. İstanbul; ISBN: 9789754209624

8. Demirbilek, T. ve Özgür, A.Ö. Elderly employment in the context of silver economy and active aging. Elderly Issues Research Journal (EIRJ).2017; 10(1), 14-28.

9. Bahar, G., Bahar, A., Savaş, A, H. Elderly and Social Services For the Elderly. Fırat Saglık Hizmetleri Dergisi.2009; 12(4), 8598.

10. Terakye, G, Güner, P. A Term with Crisis Potentıal: Elderly. Crisis Journal,. 1997;5 (2), 95-101.

11. Turkish Disabled and Elderly Services General Directorate . 2013. Avalble at: https://www.tatd.org.tr/uploads/tbl_calisma_grubu_belgeleri/5bdc0c422b9e3_tbl_calisma_grubu_belgeleri2018113514.pdf

12. Yüksel, Y.M., Kuruçay, Ö. E., Çelebi, D.Ç., Kurt, B., Ulaş, E., Yalçıntaş, H. ve Diğerleri. (2016). Intermediate and Advanced Group Programs for Individuals in Adulthood. Yüksel Y.M. (Ed). Ankara. Nobel Akademik . Perseus Book.

13. Çelebi. D.Ç., Yüksel, Y. M. Elderliness and A Review of Psychological Counseling and Guidance Services for Elderly People in Turkey. KALEM International Journal of Educational and Human Sciences. 2014;4 (2), 175-202.

14. Turkish Republic Of Northern Cyprus State Planning Organization, 2015. Last update 5 March 2019.http://www.devplan.org/Frame-tr.html

15. Konuşur.S.,L.Municipal Activities Related to the Elderly Care Services in TRNC. Institute of Health Sciences, Nursing Program, Master's Thesis. Near East University. 2015. Master's thesis. Lefkoşa. Available at: http://docs.neu.edu.tr/library/6341383200.pdf

16. Gorman, L.M., Sultan, F. Donna. Psychosocial Nursing For General Patient Care. 3 ed. E.A. Davis Company. 2008. Philadelphia.

17. Kitzinger, J. "Qualitative research: introducing focus groups", British Medical Journal. 1995; 311, 299-302. Doi:10.1136/bmj.311.7000.299 
18. Janrius Goh, M.C.,Abdin, E., Jeyagurunathan, A., Saleha, S., Sambasivam, R., Zhang, J.Y., Vaingankar, A.J., Siow Ann Chong,A.S and Subramaniam, M. Exploring Singapore's consumption of local fish, vegetables and fruits, meat and problematic alcohol use as risk factors of depression and subsyndromal depression in older adults. BMC Geriatrics.10.06.2019. https://doi.org/10.1186/s12877-019-1178-z

19. Gümüş, B, A.,Şıpkın, S., Keskin, G. Determining the Care Needs of Elderly Individuals Who Live in a Nursing Home According to the Functional Health Patterns Model). Journal of Psychiatric Nursing. 2012; 3(1):13-21. Doi: 10.5505/phd.2012.03511

20. Fiske, A., Wetherell, L.J., Gatz, M. Depression in Older Adults. Annu Rev Clin Psychol. 2009; 5: 363389.doi: 10.1146/annurev.clinpsy.032408.153621

21. Şahin, D., Aydın, A., Şimşek, N., Cabar. Yaşlııı, Depresyon ve Hemşirelik. Journal of Psychiatric Nursing, 2012;3(1):38-4. Doi: $10.5505 /$ phd.2012.43153

22. Sucuoğlu, N. (2012). Maintaining Activities of Daily Living and the State of Experiencing Depression of Elderly Living in the Centre of Nicosia, Near East University Institute of Health Science Nursing Programme, Master's Thesis. 2012. Nicossia. Available at: http://docs.neu.edu.tr/library/6252178706.pdf

23. Shin KR, Kim MY, Kim YH. Study on thelivedexperience of aging. Nursing\&HealthSciences. 2003; 5(4);245-52.

24. Mogaddam, S.L.,Foroughan, M., Mohammadi, F., Ahmadi, F., Farhadi, A., Nazari, S., Sadeghi, N. Adults Older in Perception A. RewiePaper. İranianJournal of Ageing. 2016;10(4) 202-209.

25. Hökelekli, H. Death and psycho-psychology. Uludag University Faculty of Theology Journal. 1991; 3 (3), 151- 165.

26. Yang, Y. How Doses Functiona Disability Affect Depressive Symptomes in Late Life? The Role of Perceived Social Supportand Psychological Resources, Journal of Health and Social Behavior. 2006; 47(4),355-372. doi.org/10.1177/002214650604700404

27. Karahan, A., Güven, S. Homecare for Elderly. Turkish Journal of Geriatrics. 2002; 5(4), 155-159.

28. Aközer, M., Nuhrat, C., Say, Ş. Expectations Regarding Aging Research Period in Turkey. Journal of Social Policy Studies. 2011;12 (7); 103-127.

29. Siviş, R. Anımsama Terapisi ve Illeri Yaştaki Yetişkinlerle Grupla psikolojik DanısmadakiYeri. Turkish Psychological Counseling and Guidance Journal. 2007;3(28), 129-138.

30. Potter, P.A.,Perry,A.G. OlderAdult, Fundamentals of Nursing, Concept Processan Practice,. 1997. IV. Edition, s. 569-590. St. Louis : Mosby Publisher.

31. Demir, A. The Validity and Reliability Study of the UCLA Loneliness Scale. Turkish Journal of Psychology, 1989; (23), 14-18.

32. Erci, B., Yılmaz, D., Budaki F. Effect of Self-Care Ability and Life Satisfaction on the Levels of Hope in Elderly People. Journal of psychiatric Nursing. 2017; 8(2):72-76. Doi: 10.14744/phd.2017.52714

\section{Table 1}




\begin{tabular}{|c|c|c|}
\hline Category & Theme & Sub-theme \\
\hline \multirow{4}{*}{ Psychological } & Losses & $\begin{array}{l}\text { Loss of independency } \\
\text { Loss of strength }\end{array}$ \\
\hline & Loneliness(emotional) & $\begin{array}{l}\text { Loss of spouse } \\
\text { Loss of loved ones }\end{array}$ \\
\hline & Risk of depression & $\begin{array}{l}\text { Feeling of unworthiness } \\
\text { Regret } \\
\text { Feeling of inadequacy due to physical problems } \\
\text { Lack of hope and sadness } \\
\text { Feeling low energy }\end{array}$ \\
\hline & Adaptation to being elderly & $\begin{array}{l}\text { positive attitudes/thoughts about being elderly, acceptance } \\
\text { Negative attitudes/thoughts about being elderly }\end{array}$ \\
\hline \multirow[b]{2}{*}{ Spiritual } & Anxiety about death & $\begin{array}{l}\text { Regrets about the past } \\
\text { Uncertainty about future } \\
\text { Fear of losing loved ones }\end{array}$ \\
\hline & Beliefs, values and culture & $\begin{array}{l}\text { Opinions about care and nursing homes } \\
\text { Opinions about day-care homes } \\
\text { Desire of talking about the past-Longing to past (comfort) }\end{array}$ \\
\hline \multirow{4}{*}{ Social } & Change in roles & $\begin{array}{l}\text { Loss of role } \\
\text { Becoming grandparent (responsibility) } \\
\text { Adaptation to retirement }\end{array}$ \\
\hline & Change in expectations & $\begin{array}{l}\text { Enjoying of the free time (drawback) } \\
\text { Expectations from children }\end{array}$ \\
\hline & Family problems & $\begin{array}{l}\text { communication problems with the spouse (inadequacy in family communication) } \\
\text { Burden of care due to the health issues of spouse }\end{array}$ \\
\hline & Loneliness & $\begin{array}{l}\text { Physical burden } \\
\text { Social isolation } \\
\text { Work environment and feeling of alienating from friends }\end{array}$ \\
\hline \multirow[t]{2}{*}{ Physical } & Physical losses due to elderliness & $\begin{array}{l}\text { Weakness } \\
\text { Loss of functional competence } \\
\text { Change in body image } \\
\text { Not being active }\end{array}$ \\
\hline & Illnesses & $\begin{array}{l}\text { Inability to manage chronic illness } \\
\text { Functional losses } \\
\text { Dependent to others }\end{array}$ \\
\hline
\end{tabular}

Table 1. Followingthe Focus Group Interviews, the Psychosocial Needs of Elderly 